\title{
Islam Nusantara: Islam Khas dan Akomodasi terhadap Budaya Lokal
}

\author{
Edy Susanto, Karimullah \\ Jurusan Tarbiyah STAIN Pamekasan \\ Email: edihabermas@yahoo.co.id
}

\begin{abstract}
This article is mainly to analyse background of the emerging of an Islamic thought, that is, friendly Indonesian model. This study has been conducted in order to address the spread of Islamic literalist-puritans-literalist-trans-nationalist massively and fiercely against local traditions. In this study, we look at the emerging a new Indonesian model of Islam, that is, the so called "Islam Nusantara". The Islam Nusantara is believed basically rooted from Indonesians' tradition and has already grown in the early age of Islam in this country which was introduced by the Walisongo (the nine priests). Hence, Islam Nusantara should not be seen in suspicious perspective since it has been basically familiar with cultures and characters of Indonesian nation, which are moderate and tolerant ones. Moreover, it figures out the role of Pesantren institutions, and organisations such as NU and Muhammadiyah with their various characteristics, strength and weakness, are the pioneer of Islam Nusantara heritage and cultures.
\end{abstract}

\begin{abstract}
Abstrak
Tulisan ini mencoba menganalisa latar belakang munculnya paham keagamaan Islam yang ramah khas Indonesia. Hal ini dilakukan ditengah suasana semakin massifnya penyebaran Islam literalis-puritanis skriptural-transnasionalis yang garang terhadap tradisi lokal. Dideskripsikan betapa paham yang kemudian dikenal dengan "Islam Nusantara" adalah sesuatu yang memang berakar kuat dalam tradisi bangsa Indonesia, dan sudah dikembangkan sejak masa paling dini Islam di Nusantara oleh Walisongo, sehingga Islam Nusantara tidak perlu dipandang dengan kacamata curiga karena ia telah familiar dengan budaya dan karakter bangsa Indonesia sendiri yang cenderung berwatak moderat dan toleran. Dideskripsikan pula peran pesantren, NU dan Muhammadiyah dengan berbagai kelebihan dan kekurangannya sebagai jangkar pewarisan kebudayaan Islam Nusantara.
\end{abstract}

Keywords ; Islam Nusantara, Wahabi, Puritanis, Islam akomodatif. 


\section{A. Pendahuluan}

Dalam dinamika kehidupan berbangsa dan beragama, kini sejumlah negara berpenduduk mayoritas Muslim, terutama di kawasan Timur Tengah -seperti di Irak, Suriah, Yaman, Somalia, Afganistan, Mesir dan Libya-- tengah bergolak dengan perang saudara yang tiada habisnya. Realitas demikian melahirkan pandangan steriotype tentang Islam (Islamophobia) ${ }^{1}$, sebagaimana ditegaskan oleh Profesor Machasin yakni "banyak praktik Islam di Timur Tengah yang justru mengedepankan kekerasan. Citra Islam saat ini justru didominasi kawasan Timur Tengah yang penuh konflik. Ketika pembicaraan tentang Islam mencuat, maka akan muncul persepsi buruk bahwa Islam adalah teroris dan keburukan". ${ }^{2}$

Hal senada juga ditegaskan oleh KH. Mustafa Bisri dalam khutbah Iftitah pada Mu'tamar NU ke 33 di Jombang, 17 Syawal 1436 H/1Agustus 2015 yang penulis kutip berikut ini:

Seperti diketahui, dunia dewasa ini diresahkan oleh fenomena merosotnya nilai kemanusiaan, diresahkan oleh faudla dan kekacauan seperti yang terjadi di kawasan Timur Tengah, dengan munculnya kelompok yang mengatasnamakan Islam dengan perilaku yang sangat bertentangan dengan Islam. Setiap hari, dunia disuguhi tampilan Islam yang dibawakan oleh sementara kaum muslimin yang marah. Dunia pun bertanya-tanya dimanakah perilaku rahmah dari agama yang katanya membawa ajaran rahmah

\footnotetext{
1 Runnymede Trust -sebuah Komisi Muslim Inggris dam Islam tentang mendefinisikan Islamophobia dengan is the shorthand way of referring to dread or hartred of Islam, and therefor, to fear ordislike of all or most Muslems (rasa takut dan kebencian terhadap Islam dan oleh karena itu juga pada semua Muslim). Periksa Runnymede Trust, Islamophobia: a Challenge for Us all: Report of The Runnymede Trust Commission on British Muslims and Islamophobia. (London: Runnymede Trust, 1997), hlm. 1. Istilah lain yang hampir semakna dengan islamophobia adalah Demonologi Islam. Demonologi merujuk kepada suatu perekayasaan sistematis untuk menempatkan sesuatu agar ia dipandang sebagai ancaman yang menakutkan. Dalam ilmu komunikasi, demonologi ini termasuk dalam teori penjulukan (labelling theory) yang bisa direkayasa menjadi public opinion sedemikian hebat sehingga korban misinterpretasi menjadi hancur reputasinya. Dalam kaitannya dengan Islam, demonologi merupakan sebuah perekayasaan sistematis oleh dunia Barat untuk menempatkan Islam dan umatnya agar dipandang sebagai bahaya, jahat, kejam sehingga menjadi ancaman yang sangat menakutkan. Periksa Nabiel Fuad Almusawa, "Demonologi Islam: Strategi Barat untuk Menghancurkan Islam"http://10.10.11.212/cetak.php?id=48

${ }^{2}$ Machasin, "Islam Nusantara dalam Kancah Internasional", Aula Majalah Nahdlatul Ulama Ishdar 08 SNH XXXVII Agustus 2015, h 19.
} 
itu, yang membawa ajaran kasih sayang itu. Ketika ada sementara kelompok yang mengibarkan bendera Islam sambil menghancurkan kemanusiaan, duniapun semakin mempertanyakan tentang praktik Islam yang rahmatan lil 'alamin, yang damai, yang menghargai manusia. ${ }^{3}$

\section{B. Wahabisme: "Moyang" Radikalisme-Puritan}

Faktor penyebab timbulnya kekerasan beragama di kawasan Timur Tengah tersebut oleh banyak analisis dipengaruhi oleh ajaran Wahabisme. ${ }^{4}$ Mengapa Wahabisme ? Jawabannya adalah karena Gerakan Wahabi memiliki dua hal strategis dan sinergis yaitu aliran keagamaan yang radikal dan kekuasaan politik untuk melakukan ekspansi wilayah dan penyebaran ajaran. ${ }^{5}$ Terbukti, kaum Wahabi menyebarkan ajarannya dengan kekerasan dan menggunakan politik kekuasaan dan politik sebagai alatnya. Atas dasar itu, Profesor Abu Zahrah menyebut kaum Wahabi hampir sama dengan kaum khawarij yang mengkafirkan orang-orang yang berbeda pendapat dan memerangi mereka dengan kekuasaannya, bahkan juga mirip dengan kelompok Mu'tazilah ketika berkuasa pada masa Abbasiyah yang menyebarkan ajarannya dengan menggunakan alat politik dengan cara melakukan inquisisi (mihnah). ${ }^{6}$

Selama perluasan wilayah dan penyebaran ajaran tersebut, gerakan Wahabi menyerang, merusak dan memberantas adat kebiasaan masyarakat yang mereka pandang bid'ah dan bertentangan dengan tauhid. Dalam rangka pemurnian tauhid tersebut, mereka banyak merusak simbol-simbol

\footnotetext{
3 A. Mustofa Bisri, "Islam Nusantara: Revolusi mental dan Amanat Hadratus Syaikh", Aula Majalah Nahdlatul Ulama No. 09 SNHXXXVII September 2015, h. 63.

${ }^{4}$ Ihsan Ali Fauzi, "Wahhabisme dan Sumbangan Algar: Pertanggungjawaban Penerbit", dalam Hamid Algar, Wahhabisme Sebuah Tinjauan Kritis. Terj. Rudy Harisyah Alam . (Jakarta: Democracy Project Yayasan Abad Demokrasi, 2011), h. 7 Istiilah Wahhabisme sendiri merujuk kepada nama tokoh pencetus paham keagamaan ini, yaitu Muhammad bin Abd Wahhab (1115-1201H/1703-1787 M) yang lahir di Uyainah, Najed. Istilah Wahabi ini adalah nama yang diberikan oleh lawan-,lawannya. Mereka sendiri menyebut dirinya dengan Muwahhidun (pendukung ajaran yang memurnikan Tauhid. Periksa John O. Voll. "Wahabiyah" dalam Mircea Eliade, ed. The Encyclopedia of Religion XV (New York: McMillan Publishing Company, 1993), h. 313.

5 Agus Moh. Najib, "Gerakan Wahabi: Ajaran dan Metode Penyebaran", dalam Yudian Wahyudi, ed. Gerakan Wahabi di Indonesia (Yogyakarta: Nawasea Press, 2009), h. 18.

${ }^{6}$ Periksa Muhammad Abu Zahrah, Tarikh al-Mazahib al-Islamiyah Fi al-Siyasah wa al'Aqa'id. (Beirut: Dar al-Fikr al-'Arabi, tt.), h. 238.
} 
yang dianggap akan menimbulkan kemusyrikan. ${ }^{7}$ Karena itu, Khaled Aboe el-Fadl menulis dengan nada geram mengenai Wahabisme tersebut bahwa "setiap kelompok [radikal] Islam yang hingga tingkat berbeda dikecam oleh dunia, seperti Taliban dan al-Qa'ida, amat dipengaruhi oleh pemikiran Wahabi". 8

Lebih jauh, ciri khas ajaran (fiqh) Wahabi adalah hasilnya yang bersifat pasti, kesimpulannya yang tidak bisa digugat, dan penetapannya yang bersifat tegas. Mereka menolak gagasan tentang kesetiaan terhadap mazhab hukum tertentu dan menyatakan bahwa tidak ada alasan bagi seorang Muslim untuk mengikatkan diri pada seperangkat ketetapan tertentu. ${ }^{9}$ Pandangan mereka yang demikian berimplikasi padaterutama-lahirnya sebuah kecenderungan untuk memahami Islam dalam pengertiannya yang literal, harfiyah dan skriptural. Kecenderungan demikian, oleh Wahabi telah dikembangkan sedemikian jauh sehingga menyebabkan terabaikannya dimensi "Kontekstual" dari prinsip-prinsip Islam dan tendensi seperti ini telah menghalangi sementara kaum Muslim untuk dapat secara jernih memahami pesan-pesan al-Qur'an sebagai intrumen Ilahiah yang memberikan panduan nilai-nilai etis moral bagi kehidupan manusia. ${ }^{10}$

Kaum Wahabi meyakini bahwa diri mereka tidak terlibat terutama dalam kegiatan intelektual yang mencoba mengadaptasikan pesan-pesan dan makna Islam ke dalam kondisi-kondisi sosial sekarang ini. Menurut mereka, pesan dan makna Islam tersebut sebagian besarnya sudah jelas termaktub dalam al-Qur'an dan Hadits dan hanya perlu diterapkan dalam kehidupan. Inilah keyakinan mereka tentang memperjuangkan Islam secara kaffah, yakni obsesi kembali ke masa lalu Islam secara keseluruhan tanpa melihat perubahan sosial-budaya yang dialami masyarakat Muslim sekarang ini.

Pengaruh Wahabi -dengan paham literal, skriptural atau harfiyah yang sedemikian kental--tersebut juga terjadi di Indonesia. Hal ini ditandai

\footnotetext{
${ }^{7}$ Albert Hourani, A History Of The Arab People (Cambridge: Harvard University Press, 2002), h. 258.

${ }^{8}$ Khaled M. Aboe el-Fadl, Great Theft: Wrestling Islam for The Exremist. (San Francisco: Harper Collins, 2005), h. 45.

${ }^{9}$ Khaled M. Aboe el-Fadl, Atas Nama Tuhan: Dari Fikih Otoriter ke Fikih Otoritatif. Ter. R. Cecep Lukman Yasin (Jakarta: Serambi, 2004), h. 253.

${ }^{10}$ Bahtiar Effendy, "Agama dan Politik: Mencari Keterkaitan Yang Memungkinkan antara Doktrin dan Kenyataan Empirik", dalam M. Din Syamsuddin, Islam dan Politik Orde Baru. (Jakarta: Logos Wacana Ilmu; 2001), h. xvii.
} 
dengan munculnya halaqah-halaqah di kampus dan meningkatnya jamaah-jamaah pengajian dengan pakaian yang khas dan eksklusif. ${ }^{11}$ Gerakan Islam seperti ini muncul secara besar-besaran di kota-kota dan banyak menarik minat kalangan pelajar, mahasiswa dan kelompok terdidik lainnya, ${ }^{12}$ Dalam konteks ini, Noorhaidi Hasan menegaskan:

Kaum salafi yakin bahwa umat Islam pertama-tama harus diislamkan melalui proses evolusioner bertahap yang melingkupi pendidikan (tarbiyah) dan pemurnian (tasfiyah) sebelum penerapan syari'ah secara sempurna bisa direalisasikan. Untuk memenuhi tujuan ini, mereka dengan penuh semangat berkomitmen pada kegiatan-kegiatan dakwah (dari bahasa Arab kata dasar da'a, memanggil secara umum merujuk pada pengertian mengajak manusia, yang merupakan kewajiban bagi setiap Muslim), dengan ikut serta dalam pelaksanaan halaqah dan daurah. ${ }^{13}$

Kultur demikian, sejatinya, inkoheren (tidak sesuai) dengan konteks sosio-antropologis dan basis kultural masyarakat Indonesia. Secara sosio antropologis, masyarakat Indonesia tidak mengenal gerakan keagamaan yang bersifat ideologis dan eksklusif, sebaliknya masyarakat Indonesia justru lebih suka keterbukaan, toleransi, tidak suka konflik dan

${ }^{11}$ Yang paling mencolok dari kemunculan pengaruh Wahabi adalah kemunculan pemuda yang memakai jalabiyyah (jubah panjang), imamah (sorban), isbal (pantolan yang panjangnya hanya sampai mata kaki), dan lihyah (jenggot panjang) serta kalangan perempuannya yang menggunakan niqah (bentuk pakaian warna hitam yang menyelubungi seluruh tubuh). Mereka muncul di ruang-ruang publik di berbagai kota di Indonesia. Kehadiran mereka semakin terasa, karena mereka cenderung membedakan diri dari "segala yang berlangsung". Periksa Noorhaidi Hasan, Laskar Jihad: Islam, Militansi dan Pencarian Identitas di Indonesia Pasca Orde Baru. (Jakarta: LP3ESKITLV, 2008), h. 31.

12 Al-Zastrouw Ng,, Gerakan Islam Simbolik Politik Kepentingan FPI. (Yogyakarta: LkiS, 2006), h. 1

${ }^{13}$ Hasan, Laskar Jihad, h. 32. Noorhaidi Hasan dengan sangat jitu menunjukkan bahwa pengaruh Wahabi di Indonesia terutama dimulai melalui DDII (Dewan Dakwah Islamiyah Indonesia) -organisasi dakwah yang didirikan oleh Muhammad Natsir-- yang melalui dukungan dana yang mengalir lancar dari Saudi Arabia, DDII ini tidak hanya membangun Masjid dan sekolah Islam, tetapi juga melakukan pengiriman para pemuda Indonesia untuk belajar di Universitas di Timur Tengah. Di Indonesia, agar kampanye DDII lancar, Saudi Arabia mendirikan LPBA (Lembaga pengajaran Bahasa Arab) di Jakarta tahun 1980, dalam mana lembaga inoi berubah menjadi LPIA (Lembaga Ilmu Pengetahuan Islam dan Bahasa Arab) yang tampil sebagai pusat penyebaran pengaruh Wahabisme. Ibid. h. 45-76. 
akulturatif. ${ }^{14}$ Dijelaskan bahwa masyarakat Indonesia memiliki daya serap yang tinggi dalam hal menerima ajaran agama. Hal tersebut dapat dibuktikan dengan munculnya berbagai macam praktik ritual yang kompleks dan beragam serta adanya kebersamaan hidup masyarakat dengan agama yang berbeda. Pada abad VII dan VIII Masehi misalnya, pemeluk agama Hindu-Budha dapat hidup berdampingan dan membangun suatu tradisi secara bersama-sama. Demikian juga ketika Islam masuk, tradisi tersebut tidak berubah, dan justru terjadi akulturasi dan sinkretisasi. ${ }^{15}$ Oleh karena wataknya yang demikian, agama apapun bisa masuk dan terserap dalam kehidupan masyarakat secara damai, tanpa konflik dan gejolak sosial yang berarti.

\section{Upaya Mencari Jawaban: Islam yang Membumi}

Sesungguhnya, tidak ada yang perlu disalahkan dalam mengadaptasi kebudayaan Arab ketika mengekspresikan keberagamaan atau keislaman seseorang, tetapi yang menjadi masalah adalah menggunakan ekspresi kearaban sebagai ekspresi tunggal dan dianggap sebagai paling absah dalam beragama dan berkebudayaan, sehingga ekspresi kearaban menjadi begitu dominan, bahkan menghegemoni budaya dan tradisi lain, yang berakibat pada pudar - bahkan matinya - tradisi lainnya. Lebih celaka lagi, tradisi setempat kemudian dipandang sebagai sesat (dhalal), musyrik atau bid'ah (heresy). Bagi mereka, Islam yang dicontohkan oleh salaf al-Salih merupakan bentuk keberagamaan yang paling otentik, paling benar dan ideal. Karena itu, keunikan ekspresi keberislaman masyarakat Indonesia dicerca sebagai bentuk "kejahiliyahan modern" yangjauh dari Islam yang benar, otentik dan asli. Otentisitas Islam menjadi hilang ketika ia telah dicampuri oleh unsur luar.Islam Indonesia kehilangan nilai keasliannya semenjak ia mengakomodasi dan berakulturasi dengan budaya dan tuntutan lokal. Masuknya warna budaya lokal inilah yang dipandang melahirkan bid'ah. Dengan demikian, dalam perspektif kalangan Islam otentik, Islam di Asia Tenggara -termasuk didalamnya Indonesia-dianggap sebagai Islam yang sinkretis dan nominal, atau lebih tegas lagi, Islam Nusantara hanyalah lapisan tipis di atas kebudayaan lokal, yang

\footnotetext{
${ }^{14}$ Indonesian Heritage, Vol IX, Religion and Ritual (Singapore: Archipelago Press, 1998), h. 6 .

15 Ibid.
} 
mudah mengelupas dalam timbunan budaya setempat. ${ }^{16}$ Perspektif demikian, sesungguhnya merupakan implikasi dari proses mengidentifikasi diri sebagai great tradition atau hight tradition meminjam istilah Ernest Gellner-yang memandang agama secara skripturalis, puritan dan harfiyah dan merasa diri paling benar ${ }^{17}$

Hampir semua pakar sejarah mencatat bahwa penyebaran Islam di Nusantara melalui proses difusif dan adaptif dan sebagian besar sangat menghindari metode penaklukan militer. Sebagaimana Hinduisme dan Budhisme sebelumnya, Islam "menyatu" dan secara bertahap diserap menjadi budaya lokal yang unggul di Nusantara. ${ }^{18}$ Jika di kawasan lainnya -semisal Timur Tengah, Afrika Utara, Persia, kawasan Turki-Islam datang sebagai "hakim" dengan menguasai, menegakkan hukum dan menyelesaikan persengketaan, atau dalam bahasa Gellner, Islam datang sebagai great tradition, maka di Nusantara, Islam datang sebagai "tamu" yang pada gilirannya menjadi bagian dari keluarga. Karena itu, Islam Nusantara menunjukkan karakter yang berbeda, tidak seperti yang muncul di wilayah dunia Muslim lainnya. Sebagai misal, Islam di Timur Tengah dipandang sebagai sistem sosio religius poitik yang "final", "lengkap", otoritatif yang tidak memberikan pilihan lain, selain mentaati aturan konstruksi final aturan tersebut.

Para pendakwah Islam di Nusantara menyadari bahwa Islam-sejak dari awal-hadir dalam ruang dan waktu yang sangat kasat budaya ${ }^{19}$ sekaligus berdialektika dengannya sebagai lokus transformasi yang akan dilakukannya. Karena itu, sangat wajar jika Islam menggunakan idiom-

${ }^{16}$ Periksa J.C. Van Leur, Indonesia: Trade and Society (Den Haag: Van Houve, 1955), h. 169.

${ }^{17}$ Aswab Mahasin, "Masyarakat Madanidan Lawan-Lawannya: Sebuah Mukaddimah (Kata pengantar) dalam Ernest Gellner, Membangun Masyarakat Sipil Prasyarat Menuju Kebebasan. (Bandung: Mizan, 1995), h. xi. Menurut Gellner, tradisi tinggi adalah "Islam resmi" atau Islam yang lebih dekat kepada kitab suci. Tradisi tinggi, meskipun tidak dapat dilaksanakan dalam waktu tertentu, tetap akan terus diperjuangkan untuk dilaksanakan. Maka ketika budaya-budaya lokal-yang merupakan perwjudan "tradisi rendah" (bid'ah) terancam oleh kemerosotan, kaum Muslim dengan gampang melompat ke arah tradisi tinggi dalam rangka mengatasi krisis yang tengah mereka hadapi.

18 Yahya Cholil Staquf, "Islam Merangkul Nusantara", dalam Akhmad Sahal dan Munawir Azis, ed. Islam Nusantara Dari Ushul Fiqh Hingga PahamKebangsaan. (Bandung: Mizan-Teraju Indonesia, 2015), h. 194-195.

${ }^{19}$ Abd A'la, "Islam Pribumi: Lokalitas dan Universalitas Islam dalam Perspektif NU", Tashwirul Afkar jurnal Refleksi Pemikiran Keagamaan dan Kebudayaan. Edisi No. 14 Tahun 2003, h. 86. 
idiom Arab karena ia disebarkan untuk kali pertama dalam tradisi Arab. Demikian pula, Islam sangat kaya dengan kosa kata tata niaga, karena masyarakat Arab yang menjadi lokus dakwahnya adalah masyarakat bisnis dengan tradisi tata niaga yang canggih. Islam juga sangat kaya dengan kosmologi Arab, sehingga konsep eskatologi seperti kebahagiaan diillustrasikan dengan surga yang di bawahnya mengalir sungai (jannatin tajri min tahtiha al-anhar), sesuatu yang sangat diidamkan oleh masyarakat yang dalam kesehariannya bergelut dengan suasana panas dan gersangnya padang pasir. ${ }^{20}$ Dengan demikian dapat ditegaskan bahwa aktualisasi Islam dalam sejarah telah menjadikan Islam tidak dapat dilepaskan dari aspek lokalitas, mulai dari Arab, Persia, Turki, India sampai Melayu Nusantara. Masing-masing dengan ciri khasnya sendiri.

Dalam konteks demikian inilah, gagasan "Islam yang Membumi" atau "pribumisasi Islam" menjadi layak dipertimbangkan. Dalam gagasan pribumisasi Islam tergambar bagaimana Islam sebagai ajaran yang normatif berasal dari Tuhan diakomodasikan ke dalam kebudayaan yang berasal dari manusia tanpa kehilangan identitasnya masing-masing. ${ }^{21}$ Bagi Abdurrahman Wahid, kaum Muslim Indonesia tidak perlu melakukan Arabisasi, karena Arabisasi atau proses mengidentifikasi diri dengan budaya Timur Tengah merupakan suatu hal yang mubazir dan tidak perlu. Hal demikian (Arabisasi) akan mengakibatkan tercerabutnya kita dari akar budaya kita sendiri. Bahkan lebih dari itu, Arabisasi belum tentu cocok dengan kebutuhan. ${ }^{22}$

Bagi Islam pribumi, Islam bukanlah agama yang sekali jadi, Islam tidak lahir dari lembaran dan ruang kosong. Dalam konteks ini, setidaknya terdapat beberapa argumentasi yang dapat diajukan untuk menopang hal dimaksud. Pertama, Tuhan telah memilih bahasa manusia-dalam hal ini bahasa Arab - sebagai kode komunikasi antara Tuhan dan Rasulnya, Muhammad. Dalam proses komunikasi itu, pengujar menyatakan diri dengan suatu cara pengungkapan yang khas. ${ }^{23}$ Kedua, keterlibatan

20 Moh. Mashur Abadi dan Edi Susanto, "Tradisi Ngunya Muslim Pegayaman Bali"Karsa Vol. 20 No. 2 Desember 2012, h. 228-229.

${ }^{21}$ M. Imdadun Rahmat dkk. "Islam Pribumi: Mencari Wakah Islam Indonesia", Tashwirul Afkar Jurnal Refleksi Pemikiran Keagamaan dan Kebudayaan . Edisi No. 14 Tahun 2003, h. 9.

22 Abdurrahman Wahid, Pergulatan Negara, Agama dan kebudayaan (Jakarta: Dedsantara, 2001), h. 111.

${ }^{23}$ Mohammed Arkoun, Berbagai Pembacaan Qur'an. Ter. Machasin (Jakarta: INIS, 1997),h. 80. 
Muhammad sebagai penerima pesan di satu sisi dan sebagai penafsir di sisi lain ikut menentukan proses sosial pengujaran dan tekstualisasi al-Qur'an. Muhammad bukanlah sebuah kaset rekaman yang tidak berkepribadian, melainkan orang yang cerdas, jujur dan amanah, sehingga ketika menerima wahyu, Muhammad ikut memahami,menyerap dan kemudian menguingkapkannya dalam bahasa Arab, ${ }^{24}$ ketiga, sejak turunnya, alQur'an sudah berdialog dengan realitas. Banyak sekali peristiwa yang mengiringi turunnya ayat dan yangmerupakan jawaban atas pertanyaan umat waktu itu.

Dengan mempertimbangkan situasi sosio-historis yang melingkupi firman Allah tersebut, dapat ditegaskan bahwa terdapat hubungan dialektis antara teks al-Qur'an dengan realitas budaya. Persis dalam sistem budaya yang mendasarinya inilah, al-Qur'an "terkonstruk" secara kultural dan"terstruktur" secara historis. Dalam konteks inilah, M. Imdadun Rahmat, dengan berani menyimpulkan:

...dapat ditegaskan bahwa al-Qur'an merupakan produk budaya (alMuntaj al-Tsaqafi) Ini berarti, tidak semua doktrin dan pemahaman agama dapat berlaku sepanjang zaman dan tempat, mengingat gagasan universal Islam telah mengambil dan dibentuk oleh lokus bahasa dan budaya Arab yang bersifat relatif,berdimensi lokal dan pertikular. Karena itu dapat dipahami pula, dari zaman ke zaman selalu muncul ulama yang berusdaha mengaktualkan pesan alQur'an dan tataran tradisi keislaman yang tidak mengenal batas akhir. ${ }^{25}$

\footnotetext{
${ }^{24}$ Keterlibatan Muhammad dalam hal ini berlangsung dalam dua level. Pertama, proses pengungkapannya dalam bahasa Arab, kedua, penafsiran atas al-Qur'an yang kemudian disebut Hadits. Periksa Komaruddin Hidayat, memahami Bahasa Agama: Sebuah Kajian Hermeneutik. (Jakarta: Paramadina, 1996), h. 16. Karena itu, menurut Nasr Hamed Abu Zayd, tidak bertentangan jika dikatakan bahwa al-Qur'an itu wahyu yang diturunkan Tuhan dengan teks Muhammad (muhammadan text). Periksa Wawancara M. Taufik Rahman dan Moch Nur Ikhwan dengan Nasr HamedAbu Zayd "Tafsir Tidak Pernah berhenti”, Panji Masyarakat No. 30 Tahun 1, November 1997, h. 12-14.

25 M. Imdadun Rahmat dkk. "Islam Pribumi: Mencari Wakah Islam Indonesia", Tashwirul Afkar, h. 17.
} 


\section{Islam Nusantara: Indigenisasi dan Vernakularisasi Islam Khas}

\section{Lokal}

Dalam logika sebagaimana di atas, gagasan tentang Islam Nusantara dapat dipahami, sehingga Islam nusantara merupakan perwujudan nilainilai Islam yang sudah berakulturasi dengan budaya lokal. ${ }^{26}$ Dalam konteks ini, Azyumardi Azra mendefisikan Islam Nusantara sebagai Islam distingtif sebagai hasil interaksi, kontekstualisasi, indigenisasi, dan vernakularisasi Islam universal dengan realitas sosial, budaya dan agama di Indonesia. ${ }^{27}$ Singkatnya, Islam Nusantara merupakan paham dan praktik keislaman di bumi Nusantara sebagai hasil dialektika antara teks syari' at dengan realita dan budaya setempat. ${ }^{28}$ Bahkan, lebih jauh terdapat pula yang bernada sinis dan skeptis dengan mengajukan beberapa persoalan, misalnya bukankah Nusantara merupakan wilayah pinggiran Islam (the periphery of Islam), atau Islam yang datang ke Nusantara tidak langsung disiarkan dari Arab, tetapi disiarkan oleh saudagar dari Gujarat dan Kurdistan, bahkan dari Campa dan Cina, ${ }^{29}$ sehingga Islam yang datang

26 Abdullah Ubaid \& Mohammad Bakir, "Reaktualisasi Islam Nusantara: pengantar Editor", dalam Abdullah Ubaid \& Mohammad Bakir, ed. Nasionalisme dan Islam Nusantara. (Jakarta: Kompas Lakpesdam, 2015), h. xi.

${ }^{27}$ Lihat Portal Resmi UIN Syarif Hidayatullah Jakarta, khususnya Portal Fakultas Adab dan Humaniora (FAH), tempat asal Prof. Azra berkiprah.

${ }^{28} \mathrm{KH}$. Afifuddin Muhajir, "Maksud Istilah Islam Nusantara" Aula Majalah Nahdlatul Ulama No. 08 SNHXXXVII Agustus 2015, h. 15.

${ }^{29}$ Tentang teori masuknya Islam di Nusantara, terdapat sejumlah ahli mengajukan teori bahwa sumber Islam di kepulauan Nusantara adalah anak benua India selain Arab dan Persia. Orang pertama yang mengemukakan ini adalah Pijnappel -ahli berkebangsaan Belanda dan dari Universitas Leiden-. Dia mengemukakan asal usul Islam di Nusantara ke kawasan Gujarat dan Malabar dengan alasan bahwa orang-orang Arabmazhab Syafi'i bermigrasi dan menetap di daerah-daerah tersebut yang kemudian membawa Islam ke Nusantara. Teori Pijnappel ini kemudian direvisi oleh Snouck Hurgronje yang menyebutkan bahwa ketika Islam datang memperoleh pijakan kuat di kota-kota pelabuhan India Selatan, sejumlah Muslim Dhakka banyak yang hidup di sana sebagai perantara dalam perdagangan antara Timur Tengah dan Nusantara, datang di kepulauan Melayu sebagai para penyebar Islam pertama. Berikutnya menurut Hurgronje, mereka diikuti oleh orang-orang Arab, terutama yang mengaku sebagai keturunan Nabi Muhammad dengan memakai gelar sayyid atau syarif, yang mendakwahkan Islam, baik sebagai ustadz maupun sebagai sultan. Dia berpendapat bahwa waktu yang paling mungkin bagi saat awal Islamisasi di kepulauan Melayu-Indonesia adalah abad ke-12. Periksa Azyumardi Azra, Islam Nusantara Jaringan Global dan Lokal. (Bandung: Mizan, 2002), h. 24. Lihat pula Agus Muhammad, "Islam Nusantara di tengah Gelombang 
tidak lagi murni, bahkan dekaden karena telah tercemar oleh berbagai tradisi yang dilalui. ${ }^{30}$

Sebagai akibatnya, Islam Nusantara sering dicitrakan secara negatifpejoratif-lagi-lagi bias perspektif pandangan the Great Tradition dalam bahasa Ernest Gellner-- misalnya Islam tua, Islam kolot, Islam tradisional, Islam desa, Islam di permukaan dan Islam sinkretik serta berbagai citra negatif-pejoratif lainnya. ${ }^{31}$ Bahkan, dalam pandangan para pengamat asing (Indonesianis), Islam Nusantara tampak sangat berbeda dengan Islam diberbagai belahan dunia lain, terutama dengan tata cara yang dipraktikkan di jazirah Arab. Islam, khususnya di Jawa, tidak lebih dari lapisan tipis yang dengan mudah dapat melihat ajaran dunia Timur, yang secara esensial berbeda dengan transendentalisme dan orientasi hukum Islam Timur Tengah. Praktik keagamaan orang-orang Indonesia, sering dikatakan, lebih banyak terpengaruh oleh agama India (Hindu dan Budha) yang telah lama hidup di wilayah kepulauan Nusantara, bahkan dipengaruhi agama-agama penduduk asli dengan memuja nenek moyang dan dewa-dewi serta roh-roh halus. ${ }^{32}$

Pada sisi lain, di wilayah Nusantara sendiri, hingga detik ini belum sepenuhnya mendukung harapan tersebut, sebab masih banyak permasalahan di negeri ini yang membutuhkan pembenahan tuntas mulai dari penegakan hukum, korupsi, etika politik, pemerataan ekonomi, pendidikan, keadilan sosial, hingga pergaulan hidup dengan sesama warga bangsa.

Terhadap pandangan pejoratif tersebut di atas, kalangan yang mendukung Islam Nusantara mengajukan argumentasi pula, misalnya Said Aqil Siraj yang menyatakan:

Para pendakwah Islam sejak dulu tidak serta merta melakukan "pembumihangusan" terhadap kearifan-kearifan lokal yang sudah lama berserakan di bumi Nusantara. Artinya, mereka tidak menganggap bahwa "warisan nasional" yang ada di bumi Nusantara ini perlu dihancurkan lantas diganti secara frontal dengan simbol-

Puritanisme", Tashwirul Afkar jurnal Refleksi Pemikiran Keagamaan dan Kebudayaan. Edisi No. 26 Tahun 2008, h. 25-26.

${ }^{30}$ Abdul Mun'im Dz. "Mengukuhkan Jangkar Islam Nusantara”, Tashwirul Afkar jurnal Refleksi Pemikiran Keagamaan dan Kebudayaan. Edisi No. 26 Tahun 2008, h. 3.

${ }^{31}$ Ibid., h. 2.

${ }^{32}$ Martin van Bruinessen, "Islam Lokal dan Islam Global di Indonesia", Tashwirul Afkar jurnal Refleksi Pemikiran Keagamaan dan Kebudayaan. Edisi No. 14 Tahun 2003, h. 68 . 
simbol keislaman yang literalis. Ini jelas jauh berbeda dengan apa yang dilakukan ISIS, Boko Haram atau al-Shahab saat menguasai suatu daerah, lalu melakukan penghancuran terhadap warisanwarisan sejarah yang ada, bahkan kuburan pun jadi sasaran penghancuran. Perjalanan pendakwah Islam di bumi Nusantara ini membuktikan tidak adanya pertentangan antara nasionalisme dan ajaran Islam. Mereka menyadari betul bahwa untuk bisa berdakwah, dibutuhkan tanah air yang kondusif. ${ }^{33}$

Lebih lanjut, Said Aqil menegaskan:

Islam di Indonesia tidak punya akar radikal. Munculnya radikalisme dan terorisme merupakan hasil adopsi kultur keagamaan yang datang dari luar. Katakanlah, Islam yang radikal lebih merupakan "produk impor". layaknya sebuah produk yang diimpor dari luar negeri dan kemudian dijajakan di dalam negeri. Arus komunikasi global dewasa ini yang memungkinkan orang begitu mudahnya menyerap paham-paham luaran menjadi fakta adanya pergulatan "model baru" dalam memaknai dan menindaki ajaran Islam. ${ }^{34}$

Dalam Islam Nusantara terdeskripsikan bagaimana ajaran yang secara normatif berasal dari Tuhan diakomodasikan ke dalam kebudayaan yang berasal dari manusia tanpa kehilangan identitasnya masing-masing. Dengan demikian, Arabisasi-sebagaimana telah ditegaskan-- adalah belum tentu cocok dengan kebutuhan. Islam Nusantara berusaha menjadikan agama dan budaya tidak saling mengalahkan, melainkan mewujud dalam pola nalar keagamaan yang tidak lagi mengambil bentuknya yang otentik dari agama serta berusaha mempertemukan jembatan yang selama ini memisahkan antara agama dan budaya, sehingga sudah tidak ada lagi pertentangan antara agama dan budaya. Sebagai contoh, para Wali di Jawa berusaha memperkenalkan Islam melalui tradisi, sehingga mereka perlu mempelajari kekawian (sastra klasik) yang ada serta berbagai seni pertunjukan, yang dari itu terlahir berbagain serat atau kitab. Wayang yang merupakan ritual agama Hindu yang politeis diubah menjadi sarana dakwah dan ajaran monotheis. Ini merupakan kreativitas tiada tara, sehingga seluruh lapisan masyarakat -mulai petani,

\footnotetext{
${ }^{33}$ Said Aqil Siraj, "Mendahulukan Cinta Tanah Air", Abdullah Ubaid \& Mohammad Bakir, ed. Nasionalisme dan Islam Nusantara. (Jakarta: Kompas dan Lakpesdam NU, 2015), hlm. 5

${ }^{34}$ Ibid. hlm. 6.
} 
pedagang hingga priyayi dan bangsawan — dapat diislamkan melalui jalur ini. Mereka merasa aman dengan hadirnya Islam, karena Islam hadir tanpa mengancam tradisi, budaya dan posisi mereka.

Pada titik inilah, gagasan Islam Nusantara dikembangkan lebih lanjut sebagai jawaban dari Islam otentik, Islam murni, Islam literalisskriptural, Islam transnasionalis atau Islam puritan yang ingin melakukan proyek Arabisasi di dalam setiap komunitas Muslim di seluruh penjuru dunia. Islam Nusantara dimaksudkan untuk memberikan peluang bagi keanekaragaman interpretasi dalam praktik kehidupan beragama (Islam) di setiap wilayah yang berbeda. Dengan demikian, Islam tidak lagi dipandang secara tunggal monolitik, melainkan majemuk, sehingga tidak ada lagi anggapan bahwa Islam yang di Timur Tengah sebagai Islam yang murni dan paling benar, ${ }^{35}$ karena Islam sebagai agama mengalami historisitas yang terus berproses dan berlanjut.

Lebih jauh, Islam Nusantara berusaha mengeliminasi pandangan yang menonjolkan penggunaan ekspresi kearaban sebagai ekspresi tunggal dan dianggap paling absah dan dominan dalam beragama dan berkebudayaan bahkan menghegemoni budaya dan tradisi lain, sehingga mengakibatkan tradisi tersebut -tidak hanya pudar, tetapi juga-mati. Lebih celaka lagi, tradisi setempat kemudian dianggap bid'ah dan sesat (dhalal). Sudah tentu, sikap demikian merupakan langkah pembasmian terhadap tradisi lokal, yang selama ini telah dikembangkan oleh ulama di berbagai wilayah non Arab. Karena itu, Islam Nusantara berusaha agar bagaimana berbagai ekspresi kebudayaan bisa hidup bersama dan saling memperkaya dan bukan saling menafikan. ${ }^{36}$

Karena sifatnya yang selalu berdialektika dengan realitas itulah, tradisi keagamaan dapat berubah sesuai dengan konteks sosio-kultural suatu masyarakat. Bagi Islam Nusantara, Islam yang ideal sebagaimana dibayangkan kalangan Islam puritan itu sebenarnya tidak ada. Yang ada adalah Islam yang riil, yang hidup di tengah-tengah masyarakat yang

\footnotetext{
${ }^{35}$ Bagi kalangan Islam puritan, tradisi lokal eksistensinya ditolak. Pandangan semacam ini ternyata muncul sebagai sebagai akibat cara baca mereka terhadap tradisi berdasarkan optik al-Qur'an dan Hadits yang diandaikan transenden, lengkap dan serba mencakup segala hal. Pada hal dalam kenyataannya, al-Qur'an dan hadits tersebut dikonstruk berdasarkan tradisi yangbersifat historis dan partikular. Mereka tidak memahami, bahwa ketika menerima wahyu, Muhammad ikut aktif memahami, menyerap dan kemudian mengungkapkannya dalam bahasa Arab.

${ }^{36}$ Abdul Mun'im Dz, "Mempertahankan Keragaman Budaya", Tashwirul Afkar jurnal Refleksi Pemikiran Keagamaan dan Kebudayaan. Edisi No. 14 Tahun 2003, h. 7.
} 
majemuk. Dalam konteks Indonesia, Islam yang baik -bagi Islam Nusantara-adalah Islam yang memahami kebutuhan masyarakat Indonesia, problem-problemnya dan tantangannya ke depan.

Islam Nusantara, sama sekali tidak berpretensi untuk mengangkat budaya-budaya lokal Arab untuk dicobadaratkan (dilabuhkan) di belahan bumi Nusantara. Islam Nusantara menyadari sepenuhnya bahwa universalisasi terhadap budaya lokal Arab seperti itu bukanlah suatu tindakan bijaksana, tetapi malah justru berimplikasi pada pupusnya budaya lokal. Bagi Gus Dur, proses mengidentifikasi diri dengan budaya Timur Tengah hanya akan menyebabkan tercerabutnya penduduk Indonesia dari akar budayanya sendiri, sehingga Arabisasi bukanlah suatu tindakan bijak. Yang bijaksana adalah berupaya mendialektikakan ajaran-ajaran inti Islam ke dalam budaya lokal.

Sudah tentu, tidak terhadap semua tradisi lokal, Islam Nusantara bersikap positif apresiatif. Hanya terhadap tradisi lokal yang memberikan jaminan keadilan dan kesejahteraan pada lingkungan masyarakat saja yang bersikap apresiatif, lebih jauh, tradisi lokal yang adiluhung ('urf shahih), di mata Islam Nusantara memiliki otoritas untuk mentakhshish keumuman sebuah teks, baik al-Qur'an maupun Sunnah. ${ }^{37}$ Jelasnya, bagi Islam Nusantara, tradisi yang adiluhung tidak dipandang sebagain unsur "rendah" yang tidak bernilai, melainkan dalam spasi tertentu diperhatikan sebagai sederajat belaka dengan teks agama itu sendiri.

Jika ditelisik lebih dalam, Islam Nusantara sesungguhnya mengambil semangat yang telah diajarkan oleh Walisongo dalam dakwahnya pada abad ke 15 dan ke 16 di pulau Jawa. ${ }^{38}$ Walisongo telah berhasil memasukkan nilai-nilai lokal dalam Islam yang khas. Kreativitas Walisongo ini telah melahirkan gugusan baru bagi nalar Islam Nusantara yag tidak secara harfiyah meniru Islam Arab.

Walisongo justru mengakomodasikan Islam sebagai ajaran agama yang mengalami historisasi dengan kebudayaan. Sebagai contoh, Sunan Kudus mendekati masyarakat Kudus dengan memanfaatkan simbol-

\footnotetext{
${ }^{37}$ Tradisi masuk dalam deretan sumber hukum Islam (al-Adah al-Muhakkamah). Dalam tataran tersebut menarik juga diperhatikan sebuah kaidah fikh yaitu apa yang terhampar dalam tradisi tidak kalah maknanya dengan apa yang dikemukakan oleh teks (al-Tsabit bi al 'urf ka al-Tsabit bi al-Nash). Dari kaidah ini terlihat jelas bahwa betapa para ulama telah memberikan apresiasi yang begitu tinggi terhadap tradisi.

${ }^{38} \mathrm{KH}$. Afifuddin Muhajir menegaskan bahwa Islam Nusantara adalah Manhaj Islam sebagaimana dibangun dan diterapkan oleh Walisongo serta diikuti oleh ulama Ahlus Sunnah. Periksa Muhajir, "Maksud Istilah Islam Nusantara", h. 15.
} 
simbol Hindu dan Budha, dalam mana hal itu terlihat dari bentuk arsitektur masjid Kudus, bentuk menara, gerbang dan tempat wudhu yang melambangkan delapan jalan Budha. Demikian pula Sunan Bonang yang mengubah gemelan Jawa yang saat itu kental dengan estetika Hindu menjadi bernuansa dzikir yang mendorong kecintaan pada kehidupan transenden. Kisah perseteruan antara Pandawa dan Kurawa ditafsirkan Sunan Bonang sebagai peperangan antara peniadaan (nafiy) dengan peneguhan (itsbat). Begitu pula yang dilakukan Sunan Kalijaga yang memilih kesenian dan kebudayaan sebagai sarana dakwah. Ia sangat toleran pada budaya lokal dan berpendapat bahwa masyarakat akan menjauh jika diserang pendiriannya melalui gerakan purifikasi, mereka harus didekati secara bertahap. Sunan Kalijaga menggunakan seni ukir, wayang dan gemelan sebagai sarana dakwah. Dialah pencipta baju takwa, sekatenan, gerebeg maulud, dan layang kalimasada. Sebagai akibatnya muncullah "ritual-ritual agama" yang "sudah kawin" dengan budaya masyarakat seperti tahlilan, wetonan, muludan slametan dan sebagainya.

Dari uraian di atas, dapat ditangkap beberapa hal terkait dengan Islam Nusantara. Pertama, Islam datang dengan mempertimbangkan tradisi, tradisi yang berseberangan tidak dilawan, tetapi dicoba untuk diapresiasi untuk kemudian dijadikan sarana dalam pengembangan Islam. Kedua, Islam datang tidak mengusik kepercayaan dan agama apapun, sehingga bisa hidup berdampingan dengan mereka. Ketiga, Islam datang mendinamisasi tradisi yang sudah usang, sehingga Islam diterima sebagai tradisi dan diterima sebagai agama. Keempat, Islam menjadi agama yang mentradisi, sehingga orang tidak bisa meninggalkan Islam hidup kesehariannya.

Dengan kenyataan demikian, maka dapat disaksikan betapa Indonesia menjadi negara berpemeluk Islam mayoritas. Islam menjadi agama yang dipeluk hampir seluruh lapisan masyarakat Indonesia, mulai dari kalangan perkotaan sampai dengan daerah pedalaman, bahkan daerah yang paling susah dijangkau sekalipun. Bagi yang memperoleh pengetahuan keagamaan yang memadai, mereka menjadi Islam santri yang taat, sementara bagi yang kurang memperoleh pengetahuan keagamaan -yang diidentifikasi sebagai Islam abangan, mereka secara ritual tidak taat, tetapi kukuh memegang tradisi, yang semuanya telah bernuansa Islami.

Karena itu, hadirnya Islam Nusantara ini memiliki implikasi besar dan mendalam terhadap kehidupan bermasyarakat dan berbangsa. 
Pertama, dengan kuatnya hubungan agama dan tradisi dengan bumi yang di pijak (tanah air), maka sejak awal Islam ini gigih menolak kehadiran imperialisme, baik imperialisme politik maupun imperialisme kebudayaan. Kedua, sejak awal Islam Nusantara ikut aktif dalam membela kemerdekaan, mendirikan negara termasuk ikut menyusun konstitusi nasional dengan tetap berpijak pada agama dan tradisi, sehingga lahirlah Pancasila sebagai konsessus bersama. Ketiga, dengan kecintaannya kepada tradisi dan tanah air, Islam ini terbukti dalam sejarah, yaitu tidak pernah memberontak terhadap pemerintah yang absah, karena pemberontakan ini dianggap sebagai bentuk pengkhianatan terhadap negara yang telah dibangun bersama. ${ }^{39}$

Dalam konteks demikian inilah, tawaran dan promosi konsep Islam Nusantara dalam mewujudkan tatanan Islam ramah dan rahmah tepat disosialisasikan, karena--sebagaimana ditegaskan Azra, bahwa-"Ortodoksi Islam nusantara menumbuhkan karakter wasathiyah yang moderat dan toleran. Islam nusantara yang kaya dengan warisan Islam (Islamic legacy) menjadi harapan renaisans Peradaban Islam global"40.

\section{E. Prospek Islam Nusantara: Peran Organisasi Islam, Pesantren, NU dan Muhammadiyah}

Dengan semakin berkembangnya kalangan Islam puritan yang mengusung ideologi yang sama sekali berbeda dengan Islam Nusantara, patut dipertanyakan bagaimanakah masa depan Islam Nusantara yang menjadi mainstream di tengah "kepungan" faksi Islam puritanis yang semakin mendapat tempat di ruang publik?. Di tengah "ancaman" yang semakin serius itu, masih terdapat harapan bahwa Islam Nusantara tetap akan menjadi corak dominan dalam kehidupan masyarakat Muslim Indonesia, berdasarkan hal-hal berikut ini: ${ }^{41}$

\footnotetext{
${ }^{39}$ Mun'im Dz, "Mengukuhkan Jangkar Islam Nusantara", 7-8. Bandingkan Abdullah Ubaid, "Pengantar Editor: Reaktualisasi Islam Nusantara", Abdullah Ubaid \& Mohammad Bakir, ed. Nasionalisme dan Islam Nusantara. (Jakarta: Kompas-Lakpesdam NU, 2015), h. 4.

${ }^{40}$ Portal Resmi UIN Syarif Hidayatullah Jakarta, khususnya Portal Fakultas Adab dan Humaniora (FAH),

${ }^{41}$ Agus Muhammad, "Islam Nusantara di Tengah Gelombang Puritanisme",Tashwirul Afkar Jurnal Refleksi Pemikiran Keagamaan dan Kebudayaan. Edisi No. 26 Tahun 2008. h. 45 .
} 
Pertama, puritanisme dalam arti paham yang ekstrem, keras, kejam, garang dan radikal tidak cocok bagi kehidupan masyarakat Muslim Indonesia yang secara umum memiliki karakter keagamaan yang moderat, toleran dan akomodatif. Persatuan Islam (Persis) adalah contoh kecil yang dapat dijadikan cermin, meskipun tetap bertahan hingga kini, perkembangan kelompok yang paling puritan di antara penganut paham Wahabi awal ini dapat dikatakan jalan di tempat dan tidak menunjukkan prestasi yang fenomenal. Ini berbeda dengan Muhammadiyah yang meskipun sama-sama penganut paham Wahabi-lebih moderat dan relatif mampu beradaptasi dengan perkembangan.

Kedua, konstitusi negara kita tidak memberi kesempatan bagi berdirinya Negara Islam sebagaimana dicita-citakan oleh kalangan kelompok puritanis. Akomodasi negara terhadap aspirasi kelompok ini, paling jauh, hanya sebatas Peraturan Daerah (Perda) yang sering diidentifikasi sebagai "Perda Syari'at". Ini pun jangkauannya terbatas, cenderung tidak efektif dan -bahkan — sering dijadikan alat "komoditas politik". Misalnya penerapan Perda Syariah di Bulukumba Sulawesi selatan dan di berbagai daerah lainnya. Perdaisasi Syariah Islam di Bulukumba -dan mungkin saja di daerah-daerah lainnya-menjadi semacam alat untuk menggapai kepentingan politik. Disamping itu, Perdaisasi Syari'at ini kerap kali tidak toleran terhadap tradisi lokal yang telah dipraktikkan secara turun temurun. ${ }^{42}$

Ketiga, kelompok Islam tradisional memiliki sejumlah pranata yang menjadi penopang bagi keberlangsungan dan kebertahanan ajaran dan praktik keagamaan mereka, yaitu pesantren ${ }^{43}$. Pesantren inilah yang telah

42 Periksa Syamsurijal Adhan dan Zubair Umam, "Perdaisasi Syariat Islam di Bulukumba", Tashwirul Afkar Jurnal Refleksi Pemikiran Keagamaan dan Kebudayaan, Edisi No. 20 Tahun 2006, h. 77. Lihat juga Rumadi, "Perda Syari'at Islam: Jalan Lain menuju Negara Islam", Ibid, h. 2-7

${ }^{43}$ Pesantren merupakan khazanah peradaban Nusantara yang telah ada sejak zaman Kapitayan, sebelum hadirnya agama-agama besar seperti Hindu, Budha dan Islam. Pertemuan dengan agama besar tersebut, pesantren mengalami perubahan bentuk dan isi sesuain dengan karakter masing-masing agama, tetapi misi dan risalahnya tidak pernah berubah, yaitu memberikan muatan nilai spiritual dan moral pada setiap perilaku masyarakat sehari-hari, baik dalam kegiatan sosial, ekonomi maupun kenegaraan. Periksa Said Aqil Siraj, Islam Sumber Inspirasi Budaya Nusantara Menuju Masyarakat Mutamaddun. (Jakarta: LTN NU, 2015), h. 3. Persentuhan pesantren dengan agama Islam diperkirakan sejak meluasnya dakwah Walisongo.Periksa Alwi Shihab, Islam Sufistik: Islam Pertama dan Pengaruhnya Hingga Kini di indonesia. (Bandung: Mizan, 2001), h. 221. 
mampu melahirkan tokoh-tokoh dan ulama Nusantara yang memiliki watak tasamuh (lapang dada), tawazun (seimbang), dan i'tidal (adil).. Pesantren $^{44}$, sudah tentu pesantren yang --dalam istilah Prof Abd A'lataat asas paradigma asasi ${ }^{45}$ yang tersebar di seluruh penjuru pelosok Nusantara memberikan andil yang sangat luar biasa dalam bentuk kultur moderat dalam menjalankan agama Islam. Sebegitu besar peran pesantren ini, sampai-sampai Prof A. John dan Dr. Soebardi menegaskan bahwa pesantren pada periode antara tahun 1200 dan 1600 adalah ujung tombak pembangunan Peradaban Melayu Nusantara:

Lembaga-lembaga pesantren itulah yang paling menentukan watak ke-Islaman kerajaan-kerajaan Islam, dan yang memegang peranan paling penting bagi penyebaran Islam sampai ke pelosok

\footnotetext{
${ }^{44}$ Akhir-akhir ini banyak pesantren yang tidak lagi merepresentasikan sebagai lembaga pendidikan indigenous Indonesia yang tetap menyandang ciri-ciri tradisionalnya, yakni mengkaji kitab-kitab karya ulama masa lalu (kutub al-turath) yang biasa disebut dengan pesantren salafiyah (tradisional). Pesantren tersebut justru unindigenous Indonesia dan tidak tampak padanya ciri-ciri tradisionalnya. Bagitu pula mereka tidak mengkaji kitabkitab karya ulama masa lalu yang dikenal dengan istilah kitab kuning sebagaimana pesantren pada umumnya. Pesantren tersebut senantiasa mendengungkan untuk kembali kepada al-Qur'an dan Sunnah (al-raj'u ila al-Qur'an wa al-Sunnah) dalam segala segi kehidupan, mereka berusaha keras menolak budaya dan tradisi yang selama ini telah menjadi bagian integral kehidupan bangsa ini, mereka ingin menggantinya dengan budaya dan tradisi Timur Tengah, terutama tradisi Wahabisme., selalu bersikap keras dan tidak kenal kompromi (garang) terhadap kelompok (faksi) yang tidak sepaham, mudah membi'ahkan pihak lain, dan dalam tradisi keilmuan sanbgatlah tekstualis -sehingga dengan kebiasaan tersebut,kemudian dikenal sebagai "Islam garis keras. Pesantren yang unindigenous Indonesia tersebut kemudian menamakan dirinya sebagai pesantren "salafi" yang justru mengaku sebagai pembela al-Qur'an dan Sunnah Nabi SAW dari berbagai praktik keagamaan dan kehidupan yang menyimpang. Periksa M. Misbah, "Tradisi Keilmuan Pesantren Salafi", Ibda' Jurnal Kebudayaan Islam Vol. 12 No. 2 JuliDesember 2014, h. 242. Penamaan pesantren "salafi" inilah yang kemudian menjadi membingungkan kaum awam ketika dihadapkan dengan pesantren "salaf salafiyah" yang tradisional tersebut. Pesantren salafiyah tradisional senantiasa memelihara dan mempertahankan tradisi dan budaya ke-Indonesiaan, mengakomodasi budaya lokal dan lebih mengedepankan kemashlahatan umum (al-Mashlahah al-'ammah), toleran dan tidak mudah saling menyalahkan (mengkafirkan, membid'ahkan) orang lain.

45 Paradigma asasi pesantren pada hakikatnya adalah menekankan moderasi Islam. Dalam perspektif ini, pesantren memahami Islam sebagai keimanan yang harus berujung pada praksis, sebagai keyakinan yang niscaya dilabuhkan dalam aktivitas sosial melalui dialog, kejujuran, kerendahhatian, serta berdampak besar pada kemashlahatan umat, bangsa dan sesama. Periksa Abd A'la, "Kembalikan NU ke Nilai Pesantren”, Abdullah Ubaid, Nasionalisme dan Islam Nusantara, h. 37.
} 
pedesaan. Dari lembaga-lembaga pesantren itu sejumlah manuskrip pengajaran Islam di Asia Tenggara dikumpulkan oleh pengembarapengembara pertama perusahaan-perusahaan dagang Belanda dan Inggris sejak akhir abad ke-16. Untuk dapat betul-betul memahami sejarah Islamisasi di wilayah ini, kita harus mempelajari lembagalembaga pesantren tersebut, karena lembaga-lembaga inilah yang menjadi anak panah penyebaran Islam di wilayah ini. ${ }^{46}$

HJ De Graaf dan Pigeaud juga mencatat, bahwa pesantren di abad ke 15 telah berkembang menjadi pusat keagamaan yang perannya sama sekali tidak dapat dianggap remeh dalam memperkenalkan Islam kepada penduduk, khususnya di kalangan pedalaman. ${ }^{47}$

Dalam konteks demikian, pesantren sebagai penopang dan jangkar Islam Nusantara penting melakukan pengokohan-pengokohan dalam hal: pertama, tamaddun yaitu merancang bangun pesantren sebagai model pendidikan yang terbuka, baik secara keilmuan maupun kemasyarakatan. Kedua, tsaqafah, yaitu memberikan pencerahan kepada masyarakat agar kreatif-produktif sehingga pesantren mampu menjadi agen perubahan (agent of change) yang bermanfaat dalam spektrum ke-Indonesiaan. Ketiga, hadharah membangun budaya. Di sini pesantren diharapkan mampu melestarikan dan mengembangkan tradisi adiluhung (urf alShahih) di tengah pengaruh dahsyat globalisasi yang mampu menyeragamkan budaya melalui produk teknologi.

Lalu bagaimanakah dengan peran NU dan Muhammadiyah dalam kontestasi Islam Nusantara? NU dengan segala kekurangan dan kelebihan yang dimilikinya, telah berupaya meletakkan Islam sebagai bagian yang nyaris intrisik dari budaya-budaya mensyarakat. Nilai dan ajaran Islam yang substansial diberi konstruk yang berpijak pada karakteristik lokalitas dan kultural Indonesia dengan segala seluk beluk yang mengitarinya. Kemampuan NU dalam menyikapi realitas dan perubahan kehidupan sampai batas tertentu - terletak pada nilai-nilai paradigma keberagamaan yang dianutnya Aswaja (Ahl Sunnah wa al-Jama'ah) yang sangat lentur, dinamis dan memberikan ruang yang cukup luas bagi pengembangan

46 S. Soebardi, “ The Place of Islam”, dalam McKay, ed. Studies in Indonesian History (Australia: Pitman, 1976), h. 42

${ }^{47}$ Lihat HJ. de Graaf dan TH. G. Pigeaud, kerajaan-Kerajaan Islam di Jawa: peralihan dari Majapahit ke Mataram. (Jakarta: Grafiti Pers, 1985), h. 34. 
potensi dan kreativitas untuk meletakan syari'ah selalu bersesuaian dengan konteks persoalan yang dihadapi umat manusia. ${ }^{48}$

Demikian pula dengan Muhammadiyah, yang awalnya demikian nasionalis dan njawa $^{49}$ sebagai akibat teradinya proses ekstensifikasi dalam dakwahnya -yang dengan secara gebyah uyah menganggap bidangbidang non akidah dan non ibadah sebagai bid'ah-ternyata mengakibatkan ada biaya kultural yang harus dibayar bagi gerakan pemurnian (purifikasi) yang dilakukannya. Biaya kultural itu adalah pertama, munculnya gejala individualisme yag mengancam harmoni sosial di dalam masyarakat tradisional yang sebelumnya terpelihara dengan berjanjen, tahlilan dan manakiban. Kedua, tidak terapreasiasinya tradisi dan budaya lokal. Dalam hal terakhir ini, ekstensifikasi gerakan purifikasi Muhammadiyah mempunyai efek menjadi buldozer yang menyapu bersih nafas tradisi seni tradisional, ${ }^{50}$ sesuatu yang justru sangat dipelihara oleh Muhammadiyah awal.

Sadar akan mahalnya biaya kultural yang harus dibayar oleh ekstensifikasi gerakan purifikasi tersebut, maka Muhammadiyah segera melakukan kritik internal dan pembenahan diri: Muhammadiyah sadar

${ }^{48}$ A'la, "Islam Pribumi: Lokalitas dan Universalitas Islam dalam Perspektif NU”, h. 9495. Komitmen NU dalam mengelaborasi Islam Nusantara ini begitu artikulatif dan sangat bersemangat, sehingga menjadikan Islam Nusantara sebagai tema Mu'tamar NU ke 33 di Jombang pada awal Agustus 2015.

49 Terdapat tiga kelompok utama dalam keanggotaan Muhammadiyah tahap awal (1) priyayi santri Kauman, (2) priyayi non Santri tradisional dan priyayi non santri jebolan pendidikan Barat. Priyayi tradisional umumnya bekerja sebagai abdi dalem Kraton, terutama Kraton Yogyakarta. Sedangkan priyayi tamatan pendidikan Barat bekerja sebagai pamong praja (birokrat) dan guru di sekolah pemerintah. (3) Pedagang dan pengusaha. Do minasi abdi dalem dan priyayi khususnya di Kraton Yogyakarta, berarti bahwa Muhammadiyah mengadopsi suatu sikap menarik terhadap identitas budaya Jawa. Muhammadiyah tidak bisa mengenyahkan unsur-unsur Jawa -terutama unsur-unsur budaya permukaan-dari tubuhnya secara menyeluruh. Sikapnya untuk mempertahankan tradisi grebeg Kraton Yogyakarta merupakan contoh apresiasinya terhadap budaya Jawa. Najib Burhani akhirnya sampai pada kesimpulan Muhammadiyah pada masa Ahmad Dahlan sangat apresiatif terhadap tradisi lokal, Periksa Ahmad Najib Burhani, Muhammadiyah Jawa. Ter. Izza Rohman Nahrowi (al Wasat Pblishing House, 2010), h. 126-127. Kentalnya semangat purifikasi di Muhamadiyah, terjadi ketika Ulama asli Padang Sumatera Barat H. Rasul dan KH. Mas Mansur menjadi pimpinan di Muhammadiyah. Ibid., h. xix-xx.

50 Pramono U. Tanthowi, "Muhammadiyah: Mengusung Otentisitas Membendung Lokalitas (?), Tashwirul Afkar Jurnal Refleksi Pemikiran Keagamaan dan Kebudayaan Edisi No. 14 Tahun 2003, h. 120. 
akan pentingnya menyempurnakan paham tentang kebudayaan. Muhammadiyah menyadari bahwa budaya lokal juga mengandung local wisdom sangat kaya dengan pesan-pesan kebajikan dan estetika yang dapat dijadikan sumber inspirasi bagi gerakan spiritual, moral dan sosialnya. ${ }^{51}$ Puncaknya adalah Muktamar Muhammadiyah yang ke-47 di Makassar yang mengusung tema "Islam berkemajuan" yang dalam rumusan M. Din Syamsuddin bermakna "Islam yang mampu beradaptasi, mengakomodasi, serta menyesuaikan secara tegas dengan dinamika zaman”. Ini berarti Muammadiyah dengan tegas menyatakan afiliasinya kepada salafisme ala Muhammad Abduh yang berorientasi pada pembaruan Islam yang rasionalistik, dan bukan pada salafisme ala Muhammad bin Abdul Wahhab yang berorientasi pada pemurnian Islam yang skriptural dan harfiyah. ${ }^{52}$

\section{F. Kesimpulan}

Sebagai penghujung tulisan ini, perlu digariskan beberapa hal sebagai berikut: pertama, pesan yang dibawa oleh Islam bersifat universal, tetapi pada saat yang sama, Islam juga merupakan respon atas kondisi yang bersifat khusus di tanah Arab. Dalam konteks demikian, sesungguhya Islam lahir sebagai produk lokal yang kemudian diuniversalisasikan dan ditransendensikan sehingga kemudian menjadi Islam universal. ${ }^{53}$ Kedua, seberapa pun kita yakini bahwa Islam itu wahyu Tuhan yang universal, pada akhirnya dipersepsi oleh si pemeluk sesuai dengan problem, pengalaman, kapasitas intelektual, sistem budaya dan segala bentuk keragaman masing-masing pemeluk dalam komunitasnya, dan klaim universalitas Islam tersebut yang justru membuat Islam dapat dipahami

\footnotetext{
${ }^{51}$ Seni dan tradisi sesungguhnya merupakanekspresi hidup dan kehidupan serta menjadi cermin dari kekayaan spiritualitas, moralitas dan estetika sebuah komunitas. Dalam lingkaran kecilnya, seni tradisi terbukti memiliki peran signifikan dalam mencairkan ketegangan sosial. Misalnya, tradisi "Pela Gandong" yang dapat menjadi media rekonsiliasi antara berbagai komunitas keagamaan di Maluku. Karena itu di balik keterbatasan lokalitasnya, sesungguhnya seni-tradisi juga mengandung makna universal yang paralel dengan agama dan keluhuran budi manusia. Ibid. h. 122.

52 Akhmad Sahal. "Prolog Kenapa Islam Nusantara ?", dalam Akhmad Sahal dan Munawir Azis, ed. Islam Nusantara Dari Ushul Fiqh hingga Paham kebangsaan (Bandung: Mizan-Teraju Indonesia, 2015), h. 26-27

${ }^{53}$ Yang penulis maksudkan dengan Islam sebagai produk lokal adalah Islam lahir di Arab -tepatnya di daerah Hijaz, dalam situasi Arab dan pada waktu itu ditujukan untuk menjawab persoalan-persoalan yang berkembang di daerah tersebut.
} 
dalam sistem budaya yang beragam sebagai tempat Islam akan "disemaikan".

Islam Nusantara bukanlah sekte atau aliran baru, dan tidak dimaksudkan untuk mengubah doktrin Islam. Islam Nusantara lebih merupakan sebentuk paham keislaman yang toleran, damai dan akomodatif terhadap budaya Nusantara. Islam Nusantara merupakan bentuk keislaman yang tidak akan mengajarkan pada seseorang untuk menjadi radikal, tidak mengajarkan permusuhan dan kebencian. Karakter ini untuk sebagian terbentuk karena dalam sejarahnya, dakwah Islam di Nusantara tidak dilakukan dengan memberangus tradisi, melainkan justeru merangkulnya dan sekaligus menjadikannya sebagai sarana pengembangan Islam.

Jika sebuah amalan tidak ada di rujukan tekstualnya, tetapi ia membawa kebaikan di tengah masyarakat, hal itu justru harus dilestarikan. Idza wajida nash fatsamma mashlahah, idza wajida al-Mashlahah fatsamma syar'Allah. (jika ditemukan teks, maka di sana ada kebaikan, dan jika ditemukan kebaikan, maka di sana adalah hukum Allah). ${ }^{54}$

Wa Allah ta'ala a'lam.

\section{DAFTAR PUSTAKA}

Abadi, Moh. Mashur. dan Edi Susanto, 2012. "Tradisi Ngunya Muslim Pegayaman Bali"Karsa Vol. 20 No. 2 Desember.

Adhan, Syamsurijal dan Zubair Umam, 2006. "Perdaisasi Syariat Islam di Bulukumba", Tashwirul Afkar Jurnal Refleksi Pemikiran Keagamaan dan Kebudayaan, Edisi No. 20.

A'la, Abd. 2003 "Islam Pribumi: Lokalitas dan Universalitas Islam dalam Perspektif NU", Tashwirul Afkar jurnal Refleksi Pemikiran Keagamaan dan Kebudayaan. Edisi No. 14.

A'la, Abd. 2015. "Kembalikan NU ke Nilai Pesantren", dalam Abdullah Ubaid \& Mohammad Bakir, ed. Nasionalisme dan Islam Nusantara. (Jakarta: Kompas Lakpesdam).

\footnotetext{
${ }^{54}$ KH. Ma'ruf Amin, "Lampiran Khittah Islam Nusantara”, Ahmad Sahal dan Munawir Aziz, ed. Islam Nusantara: dari Ushul Fiqh Hingga Konsep Historis. (Bandung: Mizan -Teraju Indonesia, 2015), h. 348.
} 
Almusawa, Nabiel Fuad. "Demonologi Islam: Strategi Barat untuk Menghancurkan Islam"http://10.10.11.212/cetak.php?id=48

Al-Zastrouw Ng, 2006. Gerakan Islam Simbolik Politik Kepentingan FPI. Yogyakarta: LkiS.

Amin, KH. Ma'ruf 2015. "Lampiran Khittah Islam Nusantara", Ahmad Sahal dan Munawir Aziz, ed. Islam Nusantara: dari Ushul Fiqh Hingga Konsep Historis. Bandung: Mizan -Teraju Indonesia.

Arkoun, Mohammed. 1997. Berbagai Pembacaan Qur'an. Ter. Machasin. Jakarta: INIS.

Azyumardi Azra, 2002. Islam Nusantara Jaringan Global dan Lokal. Bandung: Mizan.

Bisri, A. Mustofa. 2015. "Islam Nusantara: Revolusi mental dan Amanat Hadratus Syaikh", Aula Majalah Nahdlatul Ulama No. 09 SNHXXXVII September.

Bruinessen, Martin van. 2003. "Islam Lokal dan Islam Global di Indonesia", Tashwirul Afkar jurnal Refleksi Pemikiran Keagamaan dan Kebudayaan. Edisi No. 14.

Burhani, Ahmad Najib. 2010. Muhammadiyah Jawa. Ter. Izza Rohman Nahrowi (al Wasat Pblishing House.

Dz, Abdul Mun'im. 2003. "Mempertahankan Keragaman Budaya", Tashwirul Afkar jurnal Refleksi Pemikiran Keagamaan dan Kebudayaan. Edisi No. 14.

Dz, Abdul Mun'im. 2008. "Mengukuhkan Jangkar Islam Nusantara", Tashwirul Afkar jurnal Refleksi Pemikiran Keagamaan dan Kebudayaan. Edisi No. 26.

Effendy, Bahtiar. 2001. "Agama dan Politik: Mencari Keterkaitan Yang Memungkinkan antara Doktrin dan Kenyataan Empirik", dalam M. Din Syamsuddin, Islam dan Politik Orde Baru. (Jakarta: Logos Wacana Ilmu.

el-Fadl, Khaled M. Aboe. 2004. Atas Nama Tuhan: Dari Fikih Otoriter ke Fikih Otoritatif. Ter. R. Cecep Lukman Yasin. Jakarta: Serambi. el-Fadl, Khaled M. Aboe. 2005. Great Theft: Wrestling Islam for The Exremist. San Francisco: Harper Collins. 
Fauzi, Ihsan Ali. 2011. "Wahhabisme dan Sumbangan Algar: Pertanggungjawaban Penerbit", Hamid Algar, Wahhabisme Sebuah Tinjauan Kritis. Ter. Rudy Harisyah Alam . Jakarta: Democracy Project Yayasan Abad Demokrasi.

Graaf, HJ. de dan TH. G. Pigeaud, 1985. kerajaan-Kerajaan Islam di Jawa: peralihan dari Majapahit ke Mataram. Jakarta: Grafiti Pers.

Hasan, Noorhaidi. 2008. Laskar Jihad: Islam, Militansi dan Pencarian Identitas di Indonesia Pasca Orde Baru. Jakarta: LP3ES-KITLV.

Hidayat, Komaruddin. 1996. memahami Bahasa Agama: Sebuah Kajian Hermeneutik.. Jakarta: Paramadina.

Hourani, Albert. 2002 A History Of The Arab People. Cambridge: Harvard University Press.

Indonesian Heritage, Vol IX, 1998. Religion and Ritual. Singapore: Archipelago Press.

Machasin, 2015. "Islam Nusantara dalam Kancah Internasional", Aula Majalah Nahdlatul Ulama Ishdar 08 SNH XXXVII Agustus.

Misbah, M. 2014.“Tradisi Keilmuan Pesantren Salafi”, Ibda' Jurnal Kebudayaan Islam Vol. 12 No. 2 Juli-Desember..

Muhajir, KH. Afifuddin. 2015. "Maksud Istilah Islam Nusantara" Aula Majalah Nahdlatul Ulama No. 08 SNH XXXVII Agustus.

Muhammad, Agus. 2008. "Islam Nusantara di tengah Gelombang Puritanisme", Tashwirul Afkar jurnal Refleksi Pemikiran Keagamaan dan Kebudayaan. Edisi No. 26.

Najib, Agus Moh. 2009. "Gerakan Wahabi: Ajaran dan Metode Penyebaran", dalam Yudian Wahyudi, ed. Gerakan Wahabi di Indonesia. Yogyakarta: Nawasea Press.

Rahmat, M. Imdadun. dkk. 2003, "Islam Pribumi: Mencari Wakah Islam Indonesia", Tashwirul Afkar Jurnal Refleksi Pemikiran Keagamaan dan Kebudayaan . Edisi No. 14.

Rumadi, 2006.“Perda Syari'at Islam: Jalan Lain menuju Negara Islam”, Tashwirul Afkar Jurnal Refleksi Pemikiran Keagamaan dan Kebudayaan, Edisi No. 20. 
Runnymede Trust, 1997. Islamophobia: a Challenge for Us all: Report of The Runnymede Trust Commission on British Muslims and Islamophobia. London: Runnymede Trust.

Sahal, Akhmad, 2015 . "Prolog Kenapa Islam Nusantara ?", dalam Akhmad Sahal dan Munawir Azis, ed. Islam Nusantara Dari Ushul Fiqh hingga Paham kebangsaan. Bandung: Mizan-Teraju Indonesia.

Shihab, Alwi.2001. Islam Sufistik: Islam Pertama dan Pengaruhnya Hingga Kini di indonesia. Bandung: Mizan.

Siraj, Said Aqil. 2015 Islam Sumber Inspirasi Budaya Nusantara Menuju Masyarakat Mutamaddun. Jakarta: LTN NU.

Soebardi, S. 1976. “ The Place of Islam”, dalam McKay, ed. Studies in Indonesian History Australia: Pitman.

Staquf, Yahya Cholil. 2015. "Islam Merangkul Nusantara”, dalam Akhmad Sahal dan Munawir Azis, ed. Islam Nusantara Dari Ushul Fiqh Hingga PahamKebangsaan. Bandung: Mizan-Teraju Indonesia.

Tanthowi, Pramono U. 2003. "Muhammadiyah: Mengusung Otentisitas Membendung Lokalitas (?), Tashwirul Afkar Jurnal Refleksi Pemikiran Keagamaan dan Kebudayaan Edisi No. 14.

Ubaid, Abdullah \& Mohammad Bakir, 2015. "Reaktualisasi Islam Nusantara: pengantar Editor", dalam Abdullah Ubaid \& Mohammad Bakir, ed. Nasionalisme dan Islam Nusantara. (Jakarta: Kompas Lakpesdam.

Voll. John O. 1993. "Wahabiyah", Mircea Eliade, ed. The Encyclopedia of Religion $X V$. New York: McMillan Publishing Company.

Wahid, Abdurrahman.2001. Pergulatan Negara, Agama dan kebudayaan. Jakarta: Desantara.

Zahrah, Muhammad Abu. Tt. Tarikh al-Mazahib al-Islamiyah Fi alSiyasah wa al- 'Aqa'id. Beirut: Dar al-Fikr al-'Arabi. 